\title{
Anti-adhesive performance of CNT enriched nanofluid lubrication during turning of Aluminum 7075 alloy using textured tools
}

\section{Sadegh Elhami}

Ferdowsi University of Mashhad

Masoud Farahnakian

Islamic Azad University

Salman Khani ( $\nabla$ salmanxani@gmail.com )

Amirkabir University of Technology

\section{Research Article}

Keywords: Nanofluid, CNT, Textured tool, Turning, Al-7075

Posted Date: February 4th, 2022

DOI: https://doi.org/10.21203/rs.3.rs-1294293/v1

License: (c) (i) This work is licensed under a Creative Commons Attribution 4.0 International License.

Read Full License 


\section{Abstract}

This paper presents the effect of surface texturing and CNT enriched nanofluid lubrication on the cutting performance of cemented carbide cutting inserts during the turning of Aluminum 7075 alloy. This alloy is widely used in various industries due to its excellent properties such as high corrosion resistance, high strength to weight ratio, and good formability. Although aluminum alloys have good cutting properties because of their low strength, they adhere between tool and chip on the rake face in machining processes, and this results in the low surface finish of machined components. To solve this problem, the use of textured tools under nanofluid lubrication is proposed in this study. Firstly, different shape of textures was fabricated on the rake face, and effective texture was determined using experimental tests. Then, turning tests were carried out using the selected textured tool under CNT enriched nanofluid lubrication to enhance the cutting performance of the machining process. Results showed that the linear microgrooves perpendicular to chip flow direction have better performance in comparison to other shapes of texture. Our findings revealed that the main cutting force, built-up edge, and surface finish were reduced up to $32 \%, 37 \%$, and $19 \%$ using the selected textured tool under CNT enriched nanofluid lubrication compared to dry turning condition.

\section{Introduction}

Aluminum alloys are widely used in the aviation, automobile, marine, and machinery manufacturing industries [1] due to their excellent properties such as high corrosion resistance, high strength and stiffness to weight ratio, high electrical and heat conductivity and good formability [2]. Although aluminum alloys have good cutting properties because of their low strength, they adhere between tool and chip on the rake face in machining processes [3]. Cutting fluids are conventionally used to lessen friction and adhesion at the cutting zone in the machining process; conversely, cutting fluids are harmful to the machine operators, ruin the machine tool rails, and pollute the environment. For these reasons, there is a need to eliminate or minimize cutting fluids and shift towards dry machining to have an environment-friendly machining process. Several sustainable methods in manufacturing have been adopted for green and cleaner production to lighten the drawbacks of dry machining [4].

Developing new tool materials, optimizing cutting fluid application (e.g. cryogenic machining [5], minimum quantity lubrication machining [6], hybrid machining [7,8]), modification of traditional cutting fluid properties (e.g. nanofluid) $[9,10]$ cutting tools surface modification (e.g. surface texturing) [11] are some of the methods.

Surface texturing of cutting tools is recognized as a strategy for enhancing dry machining applications [12]. This strategy is used to enhance the tribological conditions of the mating surfaces [13]. Surface textured cutting tool helps to reduce friction coefficient through increasing lubrication capacity and decreasing tool-chip contact length. Different types of textures have been created on the cutting tool surfaces and successfully used in turning [14], milling [15], drilling [16], and thread turning [17,18] processes by researchers. 
For example, Xie et al [19] fabricated micro-grooves using micro-grinding at the rake face of cutting tools. It is shown that the cutting temperature decreases and the shear angle increases with the reducing depth of micro-grooves. Also, their findings revealed it is required the groove width is less than chip width to improve the performance of the cutting tool. Fang and Obikawa [20] fabricated five types of micro-texture on the flank face of carbide inserts in order to enhance the cooling performance of high-pressure jet coolant in turning of Inconel 718 alloy. Their results showed that the flank and crater wear of microtextured tools reduced compared with the traditional tool. In addition, the array and height of micro fins and micro pits affected the rate of tool wear. Liu et al [21] carried out dry turning on the green alumina with the flank-face textured tools and wear resistance was investigated. Results showed that the wear of the flank face of textured tools was significantly reduced in comparison with the conventional one, and the micro-grooves on the flank face parallel to the main cutting edge exhibited better flank wear resistance. It was found that the derivative-cutting phenomenon on the flank face was the mechanism responsible for decreasing flank face wear. Khani et al [17] fabricated parallel, perpendicular, crosshatched, and circular microtextures on the rake face of threading tools to optimize the texture parameters. Their results showed that the cutting force decreased by decreasing texture's distance and increasing texture depth. In addition, there was an optimum value for texture width that led to a lower value of cutting force. Also, results revealed that the microhole textured tool had better performance than other textured tools and traditional tool during the threading process. In another study carried out by Khani et al [18] the performance of textured tools filled with different solid lubricants during the threading process of Al 7075 alloy was examined. It was found that the microhole textured tool embedded with CNT powder improved the performance of the threading process and results showed that the cutting forces, built-up edge, and chip tool contact length were reduced.

Nanofluids are a solid-liquid mixture of material including nanometer-sized solid particles in a traditional fluid [22]. In recent years, nanofluids are used in many engineering applications such as heat transfer systems and machining processes due to their excellent heat transfer capabilities and tribological properties [23-25]. The literature review presented that the use of nanofluids in metal cutting enhances the heat transfer, which leads to reduced cutting forces, coefficient of friction, power consumption, tool wear, and cutting temperature $[9,10]$.

Although several studies have been conducted to investigate the effect of surface texturing on the cutting performance of cemented carbide inserts, a few studies have examined the coupling effect of nanofluid lubrication and surface texturing on the cutting performance of turning tools, and further research in this field is required. Therefore, to further improve the cutting performance of turning tools, the turning of Aluminum 7075 alloy with micro-textured tools under CNT enriched nanofluid lubrication was proposed in this study. To achieve this, four types of textures with linear and circular arrays were engraved on the rake face of the carbide cutting inserts using laser micromachining. Turning tests were carried out on aluminum 7075 bars with the non-textured, textured tools, and optimum texture was determined. Then, comparative turning tests were carried out using the selected textured tool under dry and different concentrations of CNT enriched nanofluid lubrication. 


\section{Methods}

The cutting tools in the experimental tests were cemented carbide CNMAl20408 inserts. An Nd: YAG laser (Jinan Xinchu laser Inc.) with a wavelength of $1064 \mathrm{~nm}$, repetition rate of $20 \mathrm{kHz}$, pulse duration of 10 nSec was used for the fabrication of microtextures on the rake face of the tools. Figure 1 illustrates the SEM images of the plane and textured tools. The width, distance, and depth of the microgrooves are 50 $\mu \mathrm{m}, 150 \mu \mathrm{m}$, and $10 \mu \mathrm{m}$, respectively. The tool with linear textures perpendicular to chip flow direction, linear textures parallel to the chip flow direction, circular textures, and linear crosshatched textures were nominated T-Pe, T-Pa, T-Ch, and T-C, respectively, while, the non-textured plane tool was named T0. Figure 2 shows the cross-section profile of an individual microgroove created on the rake face of the carbide insert.

Turning tests were conducted on the TB50NR Lathe equipped with cemented carbide CNMA120408 inserts and a Kennametal MCGNR164C tool holder. Cold rolled Al 7075 alloy bars with a diameter of 30 $\mathrm{mm}$ and length of $450 \mathrm{~mm}$ were used as workpieces. In turning tests cutting speed $\left(V_{c}\right)$ considered 33,47 , and $66 \mathrm{~m} / \mathrm{min}$, depth of cut $\left(a_{p}\right)$ fixed to $0.75 \mathrm{~mm}$, and feed rate $\left(a_{f}\right)$ fixed to $0.14 \mathrm{~mm} / \mathrm{rev}$. Cutting force was measured using a Kistler 9272 type piezoelectric quartz dynamometer. The surface roughness $(R a)$ of machined workpieces was measured with a PCE RT 2200 portable profilometer. The built-up edge (BUE) size was examined by utilizing a Meiji MT4000 optical microscope. Texture patterns on the rake face were examined by SEM. The experimental setup of the cutting tests was shown in Figure 3.

In order to prepare nanofluid, firstly CNT particles were added to conventional water-based coolant. Then an ultrasonic stirrer was used to disperse and homogenize the mixture of nanoparticles and base fluid. The properties of nanoparticles are presented in Table 1.

Table 1

Characteristics of CNT nanoparticles

\begin{tabular}{|lccccll|}
\hline & Diameter & Length & Purity & Bulk density & $\begin{array}{l}\text { Real } \\
\text { density }\end{array}$ & Appearance \\
\hline $\begin{array}{l}\text { Single Walled Carbon } \\
\text { Nanotube }\end{array}$ & $1-2 \mathrm{~nm}$ & $3-8 \mu \mathrm{m}$ & $>90 \%$ & $\begin{array}{l}0.17-0.30 \\
\mathrm{~g} / \mathrm{cm}^{3}\end{array}$ & $\begin{array}{l}2-3 \\
\mathrm{~g} / \mathrm{cm}^{3}\end{array}$ & $\begin{array}{l}\text { Black } \\
\text { powder }\end{array}$ \\
\hline
\end{tabular}

\section{Results And Discussion}

\subsection{Textured tools}

\subsubsection{Main cutting force}

Figure 4 shows the main cutting force at different cutting speeds for non-textured tool and different textured tools. In this chart, each bar represents the mean cutting force measured during the turning process of Al 7050 alloy. The chart shows that the cutting speed has a significant effect on the main 
cutting force. It was found that the main cutting force decreased with increasing cutting speed. This is related to the thermal softening of material at the high level of cutting speed which leads to a drop in shear strength in the shear zone [26]. In addition, shear angle rise with cutting speed. The main cutting force could be reduced with the increasing cutting speed in the cutting process as discussed below:

During the turning process total cutting force $F_{R}$ is obtained from Eq. (1):

$F_{R}=A_{W} \tau_{C}=\frac{a_{f}}{\sin \phi} \tau_{W} \mathrm{Eq}(1)$

where $A_{c}$ is the area of the shear plane, $\tau_{w}$ is the shear strength of the workpiece material, $a_{f}$ is the uncut chip thickness, and $\varphi$ is the shear angle.

Main cutting force $F_{c}$ in the turning process are related to total cutting force as the following equation:

$F_{C}=F_{R} \sin (\beta-\alpha)$ Eq (2)

where $\beta$ is the friction angle, and $a$ is the rake angle. Substituting Eq (1) in Eq (2) results main cutting force relation Eq (3):

$F_{C}=\frac{a_{f}}{\sin \phi} \tau_{W} \sin (\beta-\alpha)$ Eq (3)

Thus, according to Eq (3) decreasing in shear strength $\left(\tau_{w}\right)$ and increasing in shear angle $(\varphi)$ leads to a decrease in main cutting force.

As revealed in Figure 4, textured tools slightly reduced the main cutting force and the T-Pe with the linear micro-grooves perpendicular to chip flow direction had the lowest cutting force in comparison to the other textured tools. The results show that the average main cutting force of T-Pe at the speed of 33, 47, and 66 $\mathrm{m} /$ min reduced 10,7 , and $14 \%$ compared with the non-textured tool. It was found that the performance of $\mathrm{T}-\mathrm{Pe}$ in force reduction was better than T-Pa, T-CH, and T-C. This can be related to the more plastic deformation of chip material in parallel, cross-hatch, and circular micro-grooves, which cause more adhesion and thus higher cutting force. While micro-grooves perpendicular to the chip flow direction reduces the more contact area and therefore leads to a reduction in cutting force.

The reduction of main cutting force during using of micro-textured tools can be explained as follows:

The friction force between chip and rake face during turning process is according to Eq (4):

$F_{f}=A_{W} \tau_{C} \mathrm{Eq}(4)$

$A_{W}=l a_{W} \mathrm{Eq}(5)$

where $A_{w}$ is the tool and chip contact area, $\tau_{c}$ is the shear strength of tool and chip interface, / is the tool and chip contact length, and aw is the chip width. As shown in Figure 5, the contact length of tool and chip is equal to: 
$l_{e}=1-n w_{g} \approx n p_{g} \mathrm{Eq}(6)$

where / denotes the contact length, $l_{e}$ denotes the effective contact length, $w_{g}$ is the width of microgrooves, $p_{g}$ is the distance of microgrooves, and $n$ denotes the number of grooves in the contact area. According to $\mathrm{Eq}(6)$, effective contact length reduces by generating microgrooves on the rake face, therefore, contact area $A_{w}$ and friction force $F_{f}$ decreases. On the other hand, the main cutting force is related to the friction force as follows:

$F_{f}=F_{R} \sin (\beta) \mathrm{Eq}(7)$

$F_{C}=F_{R} \cos (\beta-\alpha) \mathrm{Eq}(8)$

$F_{C}=F_{f} \frac{\cos (\beta-\alpha)}{\sin (\beta)} \operatorname{Eq~(9)~}$

Thus, it can be deduced that the main cutting force $F_{c}$ reduces by decreasing friction force $F_{f}$

\subsubsection{Surface Roughness}

Figure 6 shows the surface roughness Ra for four types of textured tools and non-textured tool. As revealed in this chart, the surface roughness of machined parts improved with increasing cutting speed. This is due to the fact that the built-up edge size decreases with increasing cutting speed and the machining condition becomes more stable, hence, the surface finish improves [27].

Results show that the fabrication of the microtextures on the rake face of the cemented carbide tools has no significant effect on the surface roughness, while T-Pe has better performance in comparison with other textured tools.

\subsubsection{Built-up edge}

Figure 7 demonstrates the size of the built-up edge for different tools. It was evident that the BUE for textured tools is lower than the non-textured tool. As shown in this figure, the height of BUE for the nontextured tool (T0) was $567 \mu \mathrm{m}$, while it was $460,363,326$, and $284 \mu \mathrm{m}$ for T-C, T-Pa, T-Ch, and T-Pe tools, respectively, which was reduced by $19,36,43$, and $50 \%$, respectively, Therefore, adhesion of work material on the rake face reduced using micro-textured tools. As discussed above, the friction force between chip and tool reduces by surface texturing of rake face, and therefore, heat generation decreases, and this results in low adhesion of work material on the rake face.

The results of dry turning tests with different textured tools and traditional tool showed that the T-Pe tool with linear microgroove perpendicular to chip flow direction improved performance of cutting process. In order to evaluate the effect of nanofluid lubrication on the performance of the cutting process, experimental turning tests were performed with the selected tool under nanofluid lubrication, and the results are presented below. 


\subsection{NANOFLUID EFFECT}

\subsubsection{Main cutting force}

The effect of CNT enriched nanofluid lubrication on the main cutting force is presented in Figure 8. The results of experiments showed that the $F_{c}$ was decreased up to $21 \%$ and $32 \%$ by using $1 \%$ and $3 \%$, CNT nanofluid, respectively, compared to dry cutting with the T-Pe textured tool. Therefore, an increase in the nanoparticle concentration enhanced nanofluid lubrication capability. As shown schematically in Figure 9, carbon nanotubes that are dispersed in nanofluid, penetrate into the chip and tool contact area and can act as nano-bearings, hence, relative motion between chip and tool approaches from slipping to rolling. Indeed, reduction in friction and cutting force can be attributed to the nano-bearing effect that is based on the roiling of carbon nanotubes.

\subsubsection{Surface Roughness}

The surface roughness Ra of machined workpieces with T-Pe textured tools under different lubrication conditions is shown in Figure 10. As mentioned previously, surface texturing of the rake face has no significant effect on the surface finish, but it was improved using the T-Pe textured tool under CNT enriched nanofluid lubrication condition. As presented in this chart, Ra was improved $15 \%$ and $19 \%$ by using $1 \%$ and $3 \%$ concentration nanofluids in comparison to dry machining with the T-Pe textured tool. It can be related to the stable cutting condition during the turning process with T-Pe under nanofluid lubrication. Dynamic force plots for different tools are shown in Figure 11. As shown in this figure, the fluctuation of cutting force in the T-Pe tool with CNT nanofluid lubrication was smaller than in dry condition, and this led to a more stable cutting condition, hence better surface finish was obtained.

\subsubsection{Built-up edge}

The effect of surface texturing and nanofluid lubrication on the built-up edge size is shown in Figure 12. Results revealed that the significant reduction in BUE size was observed by using CNT enriched nanofluid coolant during the turning process with T-Pe textured cutting tool. As mentioned previously, adding CNT nanoparticles to base coolant improves the tribological performance of mating surfaces, hence, the friction coefficient between chip and tool decreases and, in turn, friction force at the rake face. Therefore, by decreasing friction force, heat generation reduces and this can alleviate the adhesion of work material on the rake face. It was shown that by increasing the nanoparticle concentration from $1-3 \%$, compared to dry cutting with the textured tool T-Pe, the decrease in BUE size increased from $22-37 \%$. This can be attributed to the fact that nanoparticle concentration affects the thermal characteristics of nanofluids. Thermal conductivity $(k)$ and convection coefficient $(h)$ of nanofluids increase with increasing nanoparticles concentration $[28,29]$, thus, extra heat can be moved from the cutting zone, therefore adhesive wear reduces.

\section{Conclusion}


In this study, the influence of surface texturing and CNT enriched nanofluid lubrication on the cutting performance of cemented carbide cutting inserts during the turning of Al 7075 alloy was investigated using experimental tests. According to findings, CNT enriched nanofluid has the capability of reducing cutting force and built-up edge size. Based on the results of this study, the following conclusions could be drawn.

- The T-Pe tool with the linear microgrooves perpendicular to the chip flow direction had the lowest cutting force in comparison to the other textured tools and non-textured tools. The average main cutting force reduced up to $14 \%$ compared with the non-textured tool using the T-Pe tool under dry cutting condition.

- Results show that the fabrication of the microtextures on the rake face of the cemented carbide tools has no significant effect on the surface roughness, while T-Pe has better performance in comparison with other textured tools.

- Height of BUE for T-C, T-Pa, T-Ch, and T-Pe tools reduced $19,36,43$, and $50 \%$, respectively, in comparison to the non-textured tool under dry cutting condition.

- An increase in the nanoparticle concentration enhanced nanofluid lubrication capability; by increasing the concentration of CNT nanoparticles in the base cutting fluid from 1-3\%, Fc reduced $21 \%$ and $32 \%$ as compared to dry cutting with the textured tool T-Pe.

- Increasing the nanoparticle concentration from 1-3\%, decrease in BUE size increased from $22-37 \%$, as compared to the dry cutting condition with T-Pe textured tool.

- Surface finish was improved up to $20 \%$ and $30 \%$ by using $1 \%$ and $3 \%$ concentration CNT nanofluids. This is related to the stable cutting condition during the turning process with T-Pe under nanofluid lubrication.

\section{Declarations}

\section{Data availability}

All data generated or analyzed during this study are included in this published article.

\section{References}

1. Xing, Y., Deng, J., Wang, X., Ehmann, K. \& Cao, J. Experimental Assessment of Laser Textured Cutting Tools in Dry Cutting of Aluminum Alloys. J. Manuf. Sci. Eng. 138, 071006, doi:10.1115/1.4032263 (2016).

2. Kvackaj, T. Aluminium Alloys: Theory and Applications. (BoD-Books on Demand, 2011).

3. Byrne, G., Dornfeld, D. \& Denkena, B. Advancing cutting technology. CIRP Ann. 52, 483-507 (2003).

4. Chetan, Ghosh, S. \& Venkateswara Rao, P. Application of sustainable techniques in metal cutting for enhanced machinability: a review. J. Cleaner Prod. 100, 17-34, doi:10.1016/j.jclepro.2015.03.039 (2015). 
5. Danish, M. et al. Environmental, technological and economical aspects of cryogenic assisted hard machining operation of inconel 718: A step towards green manufacturing. J. Cleaner Prod., 130483 (2022).

6. Gupta, M. K. et al. Measurement and analysis of machining induced tribological characteristics in dual jet minimum quantity lubrication assisted turning of duplex stainless steel. Measurement 187, 110353 (2022).

7. Masoud, F., Mohammad Reza, R. \& Farid Reza, B. Multi-constrained optimization in ultrasonicassisted turning of hardened steel by electromagnetism-like algorithm. Proc IMechE, Part B: J Engineering Manufacture 229, 1933-1944, doi:10.1177/0954405414542489 (2014).

8. Elhami, S., Razfar, M., Farahnakian, M. \& Rasti, A. Application of GONNS to predict constrained optimum surface roughness in face milling of high-silicon austenitic stainless steel. Int. J. Adv. Manuf. Technol. 66, 975-986 (2013).

9. Khan, A. M. et al. Holistic sustainability assessment of hybrid Al-GnP-enriched nanofluids and textured tool in machining of Ti-6Al-4V alloy. Int. J. Adv. Manuf. Technol. 112, 731-743 (2021).

10. Zhang, L., Guo, X., Zhang, K., Wu, Y. \& Huang, Q. Enhancing cutting performance of uncoated cemented carbide tools by joint-use of magnetic nanofluids and micro-texture under magnetic field. J. Mater. Process. Technol. 284, 116764 (2020).

11. Baskar, N., BN, V. H. \& Sankaran, R. performance of cutting tool with cross-chevron Surface texture filled with Green Synthesized Aluminium oxide nanoparticles. Sci. Rep. 9, 1-9 (2019).

12. Sharma, V. \& Pandey, P. M. Recent advances in turning with textured cutting tools: A review. J. Cleaner Prod. 137, 701-715, doi:10.1016/j.jclepro.2016.07.138 (2016).

13. Conradi, M., Drnovšek, A. \& Gregorčič, P. Wettability and friction control of a stainless steel surface by combining nanosecond laser texturing and adsorption of superhydrophobic nanosilica particles. Sci. Rep. 8, 1-9 (2018).

14. Sivaiah, P., Ajay Kumar G, V., Singh M, M. \& Kumar, H. Effect of novel hybrid texture tool on turning process performance in MQL machining of Inconel 718 superalloy. Mater. Manuf. Process. 35, 61-71, doi:10.1080/10426914.2019.1697444 (2020).

15. Arumugaprabu, V. et al. Performance of surface-textured end-mill insert on AISI 1045 steel. Mater. Manuf. Process. 34, 18-29, doi:10.1080/10426914.2018.1512119 (2019).

16. Niketh, S. \& Samuel, G. L. Surface texturing for tribology enhancement and its application on drill tool for the sustainable machining of titanium alloy. J. Cleaner Prod. 167, 253-270, doi:10.1016/j.jclepro.2017.08.178 (2017).

17. Khani, S., Razfar, M. R., Haghighi, S. S. \& Farahnakian, M. Optimization of microtextured tools parameters in thread turning process of aluminum 7075 aerospace alloy. Mater. Manuf. Process., 19, doi:10.1080/10426914.2020.1772485 (2020).

18. Khani, S., Shahabi Haghighi, S., Razfar, M. R. \& Farahnakian, M. Improvement of thread turning process using micro-hole textured solid-lubricant embedded tools. Proc IMechE, Part B: J Engineering Manufacture 235, 1727-1738, doi:10.1177/09544054211019929 (2021). 
19. Xie, J., Luo, M. J., Wu, K. K., Yang, L. F. \& Li, D. H. Experimental study on cutting temperature and cutting force in dry turning of titanium alloy using a non-coated micro-grooved tool. Int. J. Mach. Tools Manuf. 73, 25-36, doi:10.1016/j.ijmachtools.2013.05.006 (2013).

20. Fang, Z. \& Obikawa, T. Cooling performance of micro-texture at the tool flank face under high pressure jet coolant assistance. Precis. Eng. 49, 41-51, doi:10.1016/j.precisioneng.2017.01.008 (2017).

21. Liu, Y. et al. Wear resistance of carbide tools with textured flank-face in dry cutting of green alumina ceramics. Wear 372-373, 91-103, doi:10.1016/j.wear.2016.12.001 (2017).

22. Mbambo, M. C. et al. Thermal conductivity enhancement in gold decorated graphene nanosheets in ethylene glycol based nanofluid. Sci. Rep. 10, 14730, doi:10.1038/s41598-020-71740-1 (2020).

23. Barzegar Gerdroodbary, M. Application of neural network on heat transfer enhancement of magnetohydrodynamic nanofluid. Heat Transfer-Asian Research 49, 197-212 (2020).

24. Nguyen, T. K. et al. Influence of various shapes of CuO nanomaterial on nanofluid forced convection within a sinusoidal channel with obstacles. Chemical Engineering Research and Design 146, 478-485 (2019).

25. Manh, T. D., Bahramkhoo, M., Gerdroodbary, M. B., Nam, N. D. \& Tlili, I. Investigation of nanomaterial flow through non-parallel plates. Journal of Thermal Analysis and Calorimetry 143, 3867-3875 (2021).

26. Trent, E. M. \& Wright, P. K. Metal cutting. (Butterworth-Heinemann, 2000).

27. Armarego, E. \& Brown, R. H. The machining of metals. 437 (PRENTICE-HALL INC, 1969).

28. Khajehzadeh, M., Moradpour, J. \& Razfar, M. R. Influence of nanofluids application on contact length during hard turning. Mater. Manuf. Process. 34, 30-38 (2019).

29. Khajehzadeh, M., Moradpour, J. \& Razfar, M. R. Influence of nanolubricant particles' size on flank wear in hard turning. Mater. Manuf. Process. 34, 494-501 (2019).

\section{Figures}




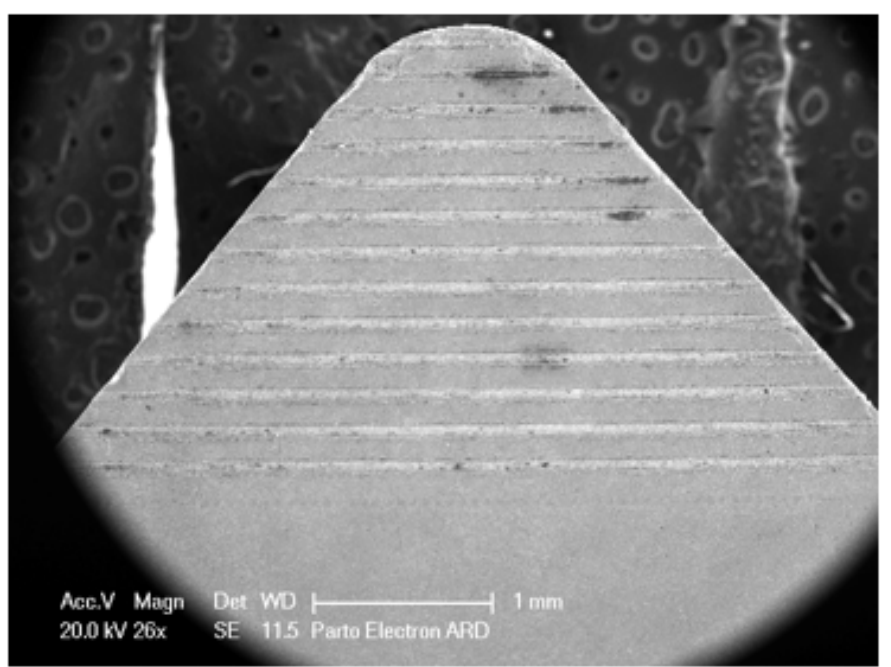

$\mathrm{T}-\mathrm{Pe}$

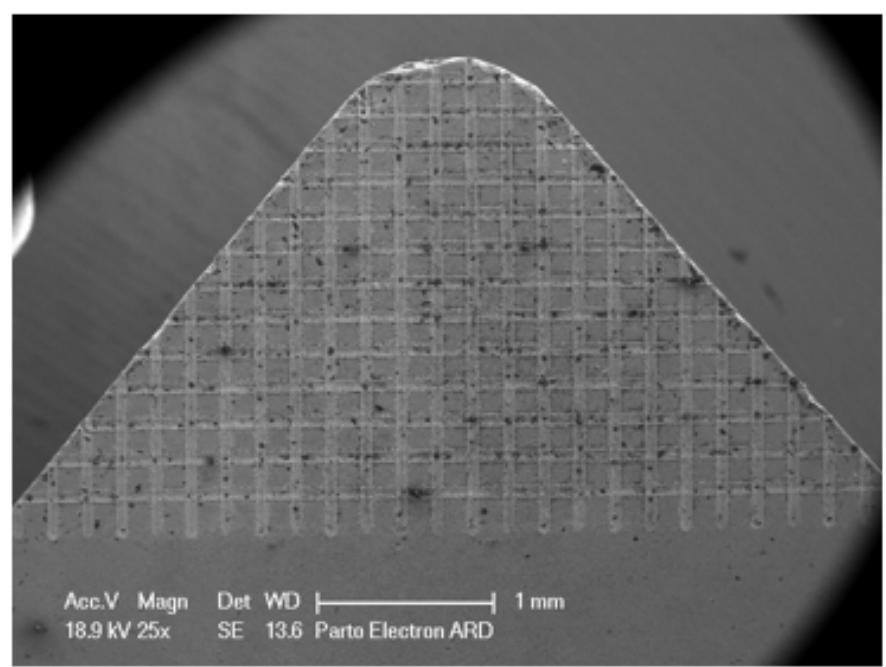

$\mathrm{T}-\mathrm{Ch}$

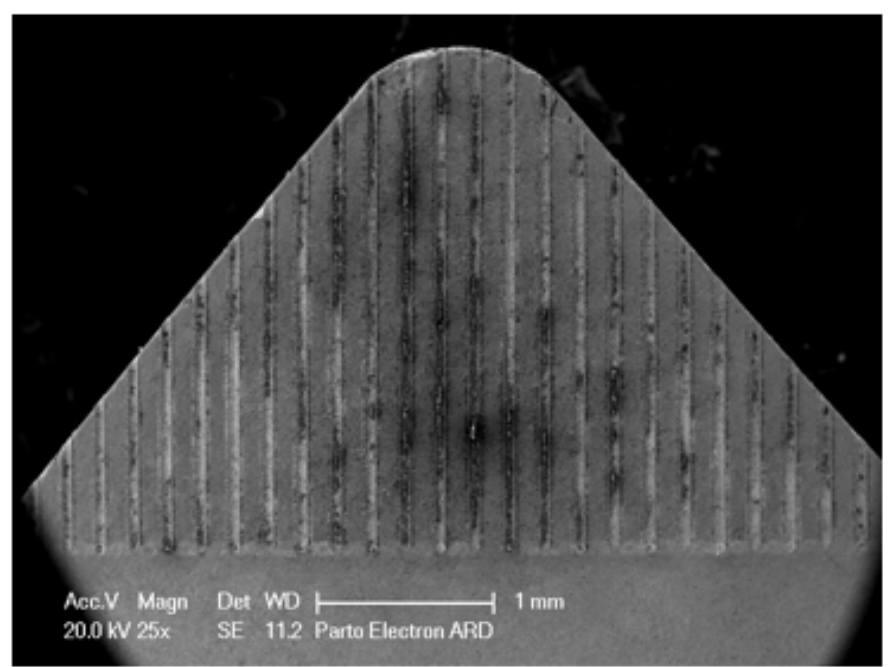

$\mathrm{T}-\mathrm{Pa}$

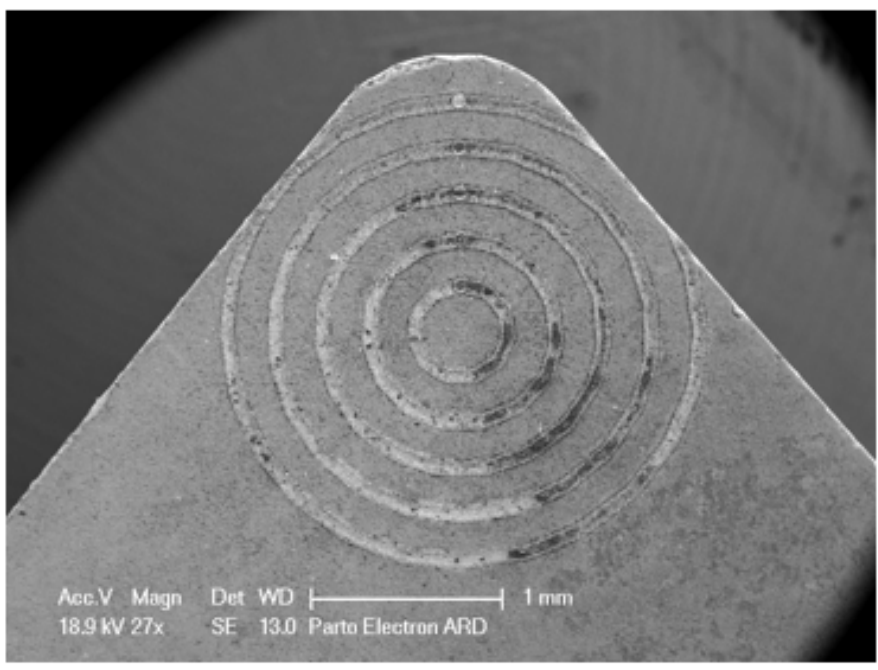

$\mathrm{T}-\mathrm{C}$

Figure 1

SEM images of microtextures created at the rake face of carbide tools 

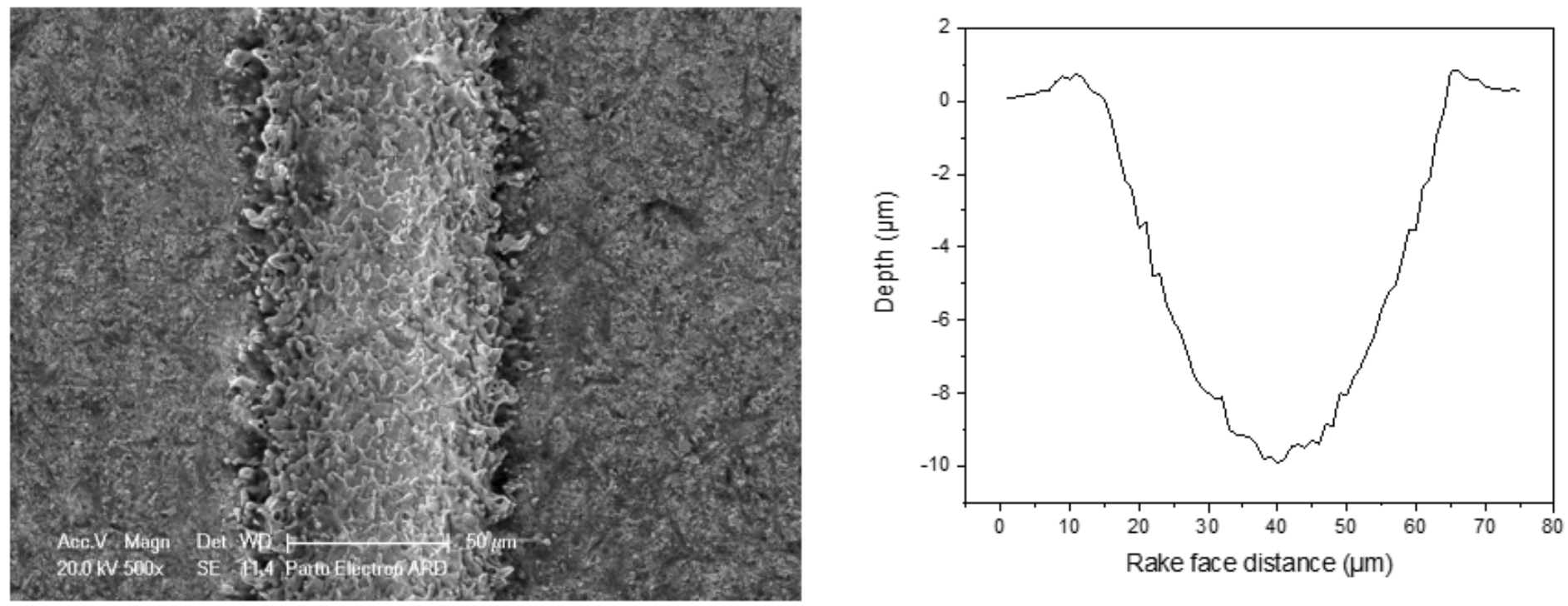

Figure 2

Profile of cross section of a microgroove

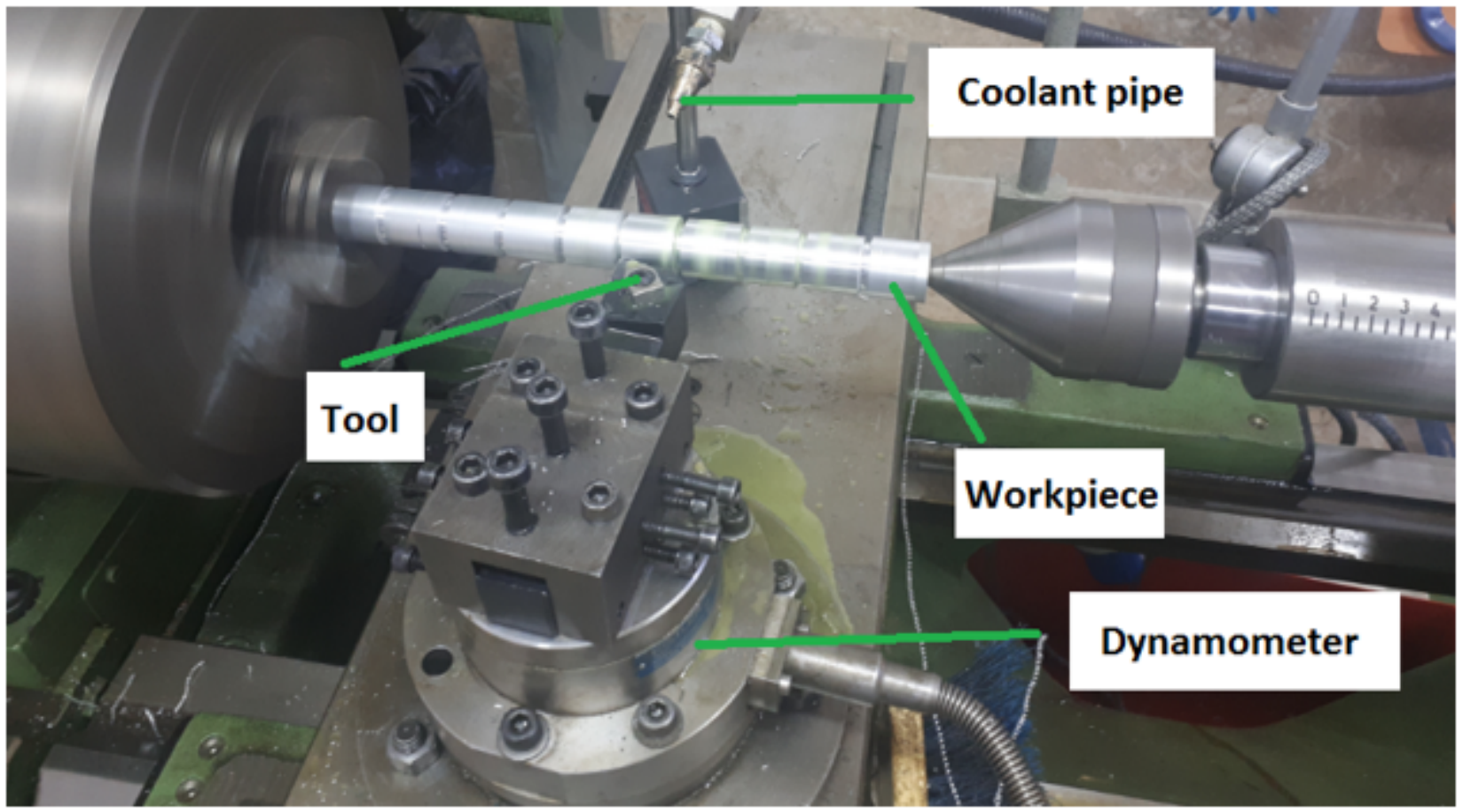

Figure 3

Experimental setup of the cutting tests 


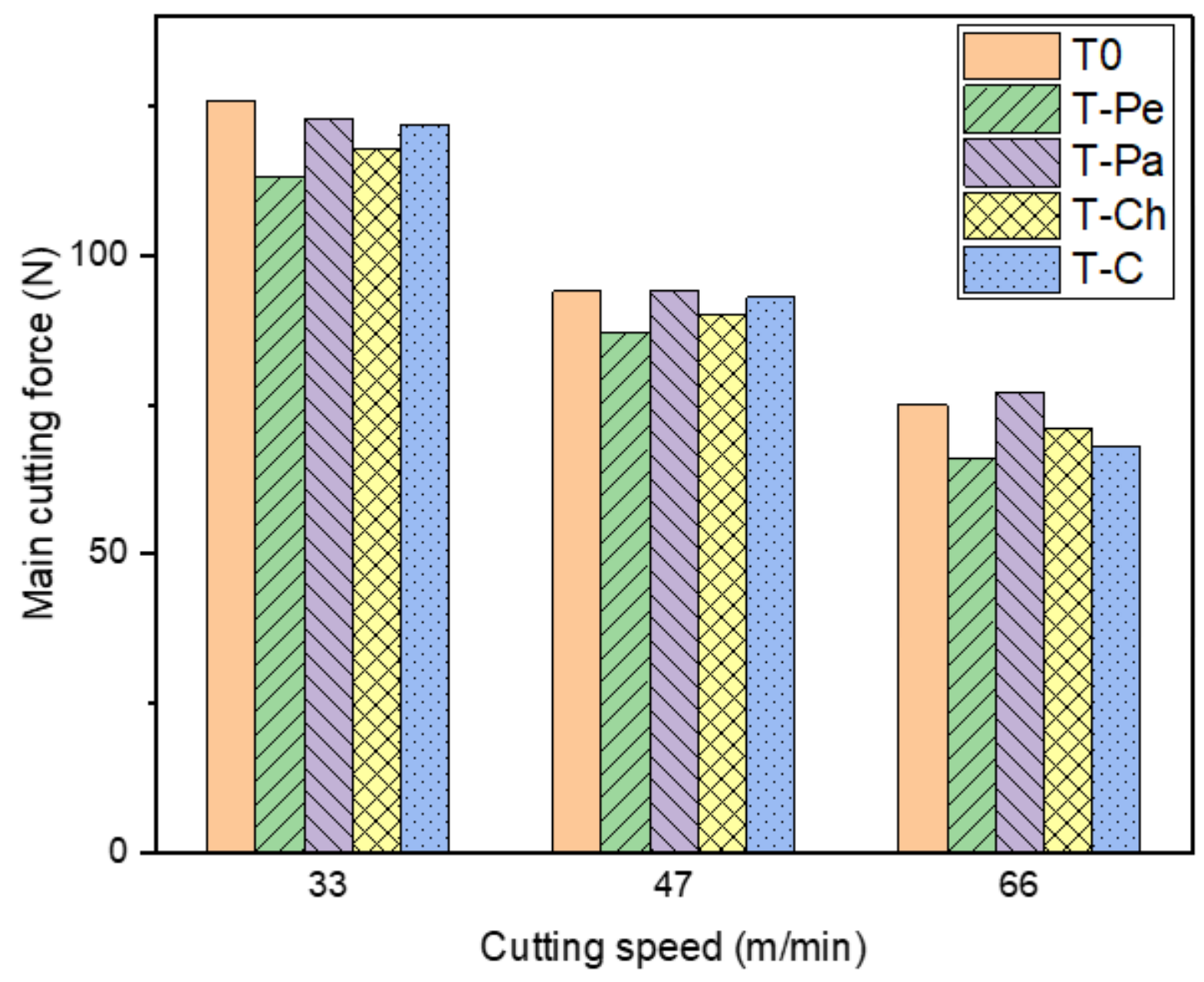

Figure 4

Main cutting force for five type of cutting tools at different cutting speeds 


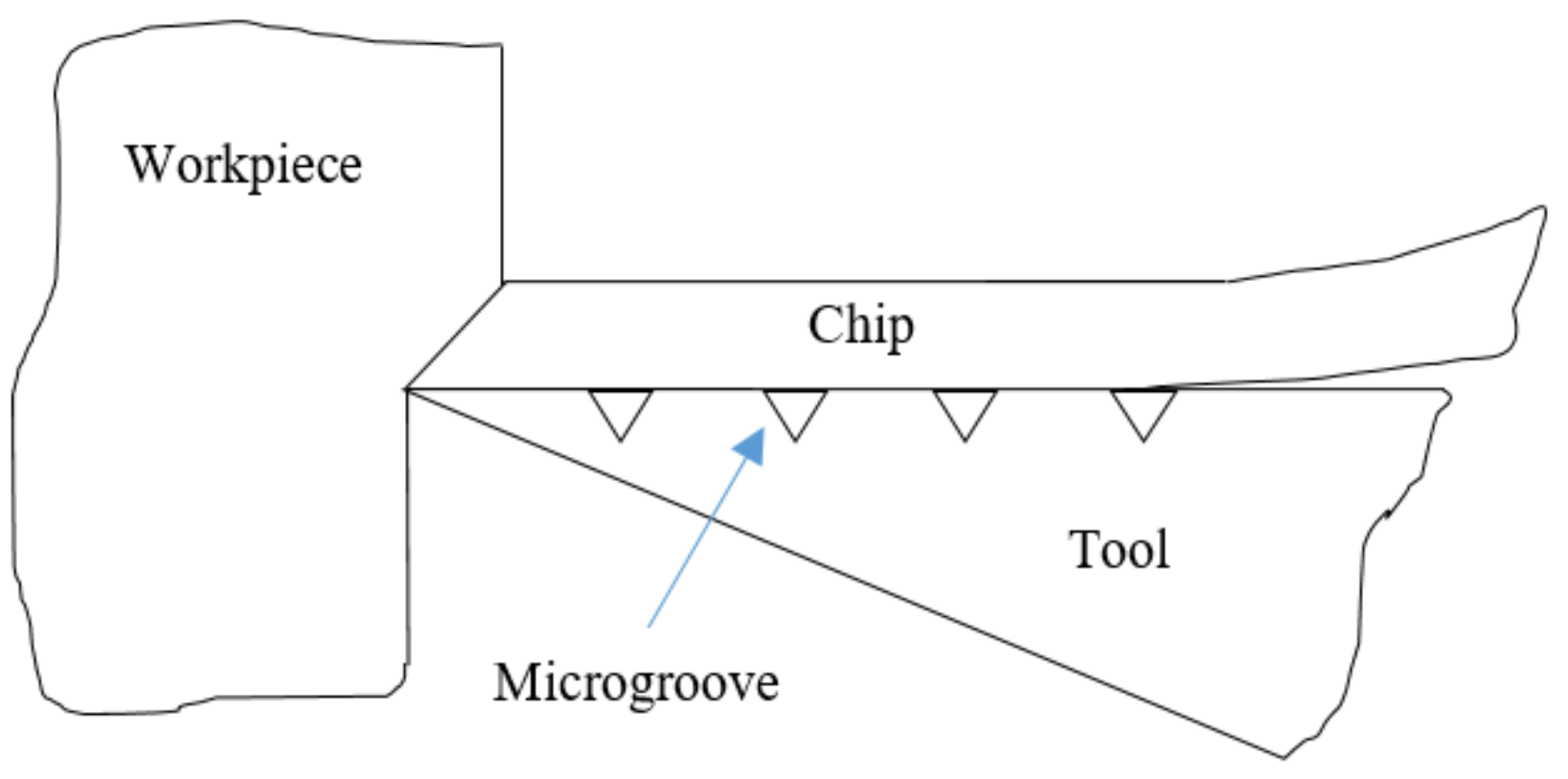

Figure 5

Schematic of chip tool contact length for textured tool

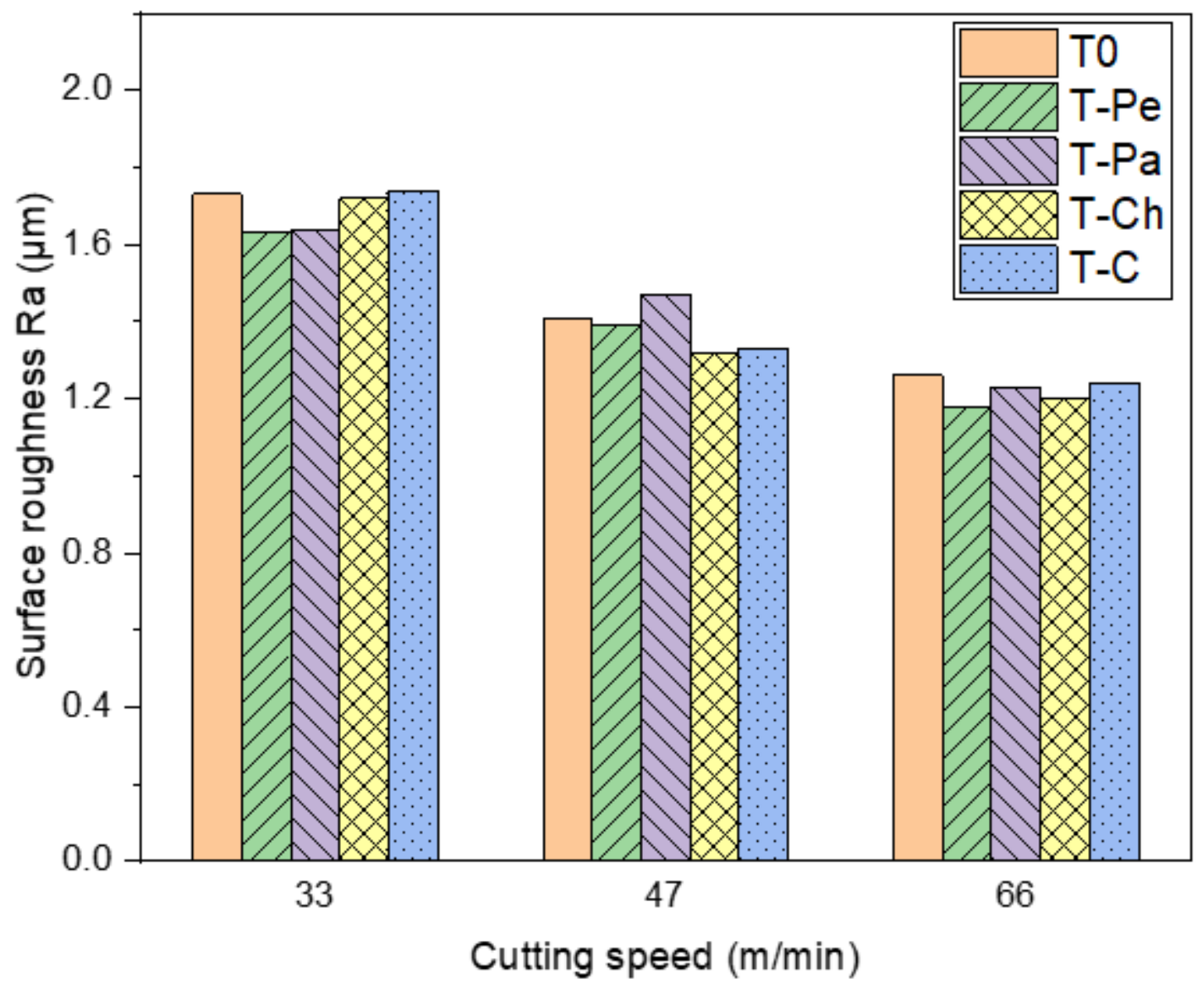


Figure 6

Surface roughness for five type of cutting tools at different cutting speeds

T0

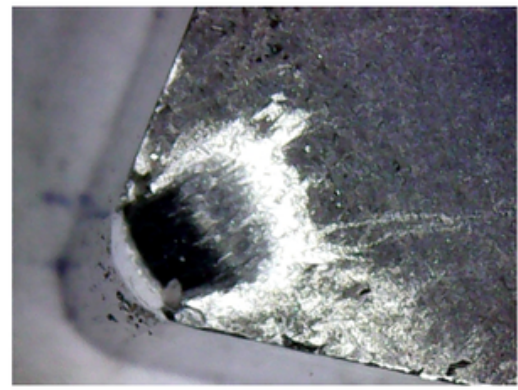

T-Pe

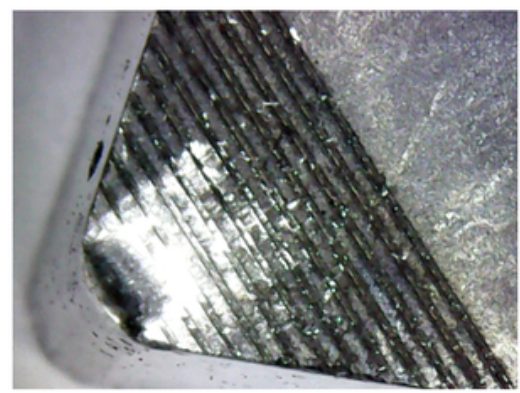

T-Pa

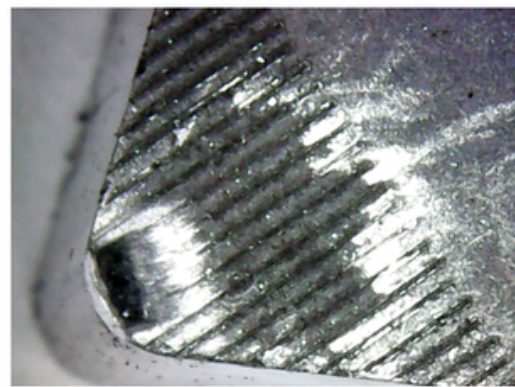

T-Ch

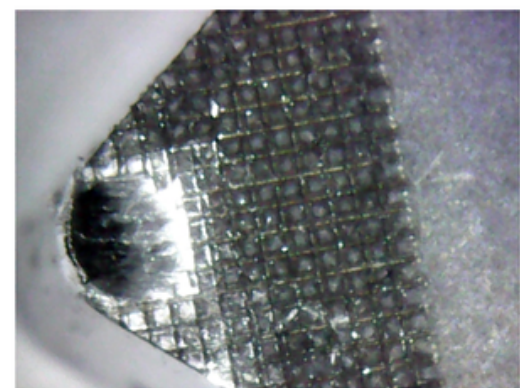

T-C

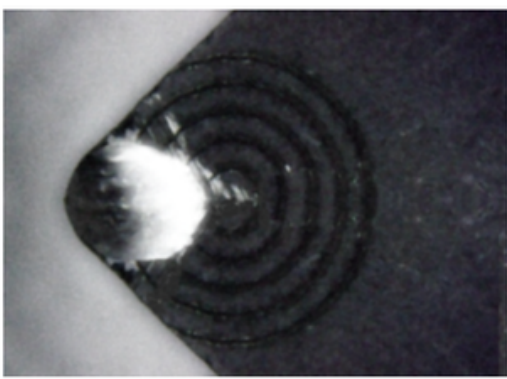

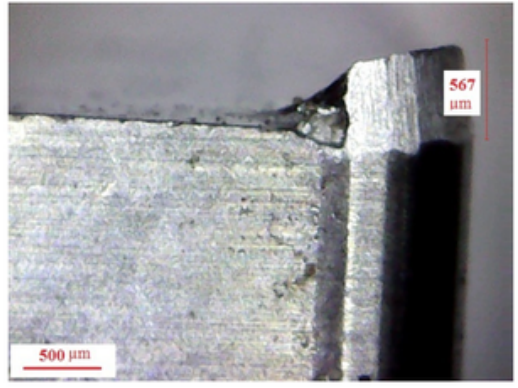
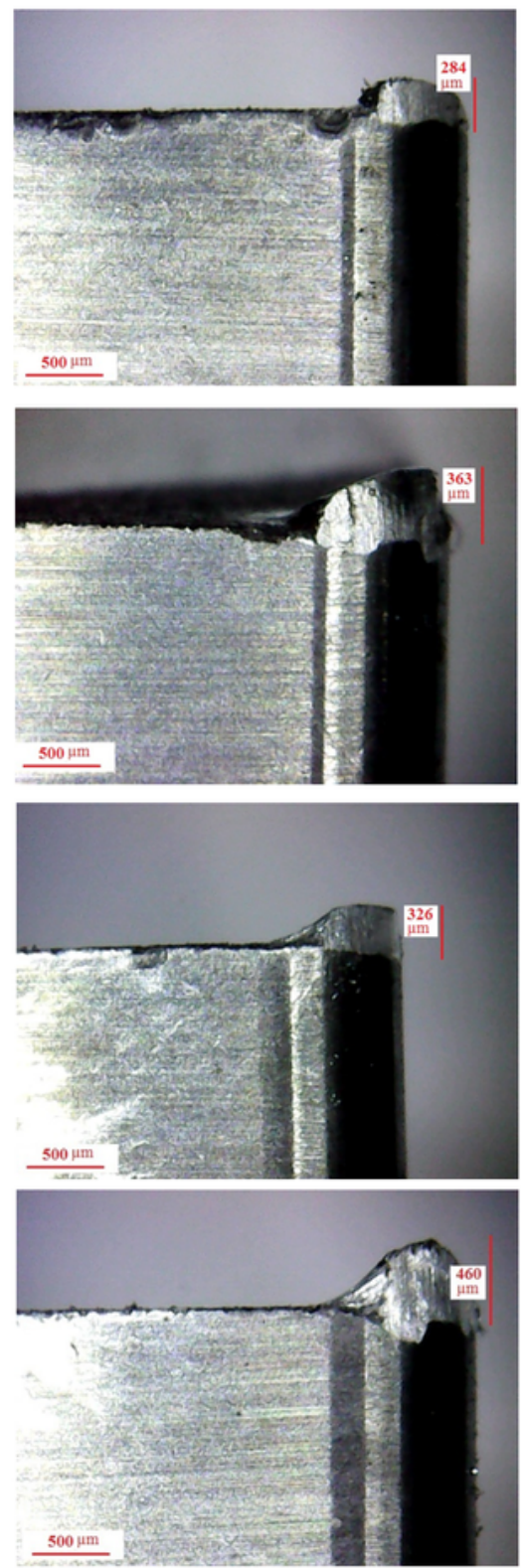

Figure 7 


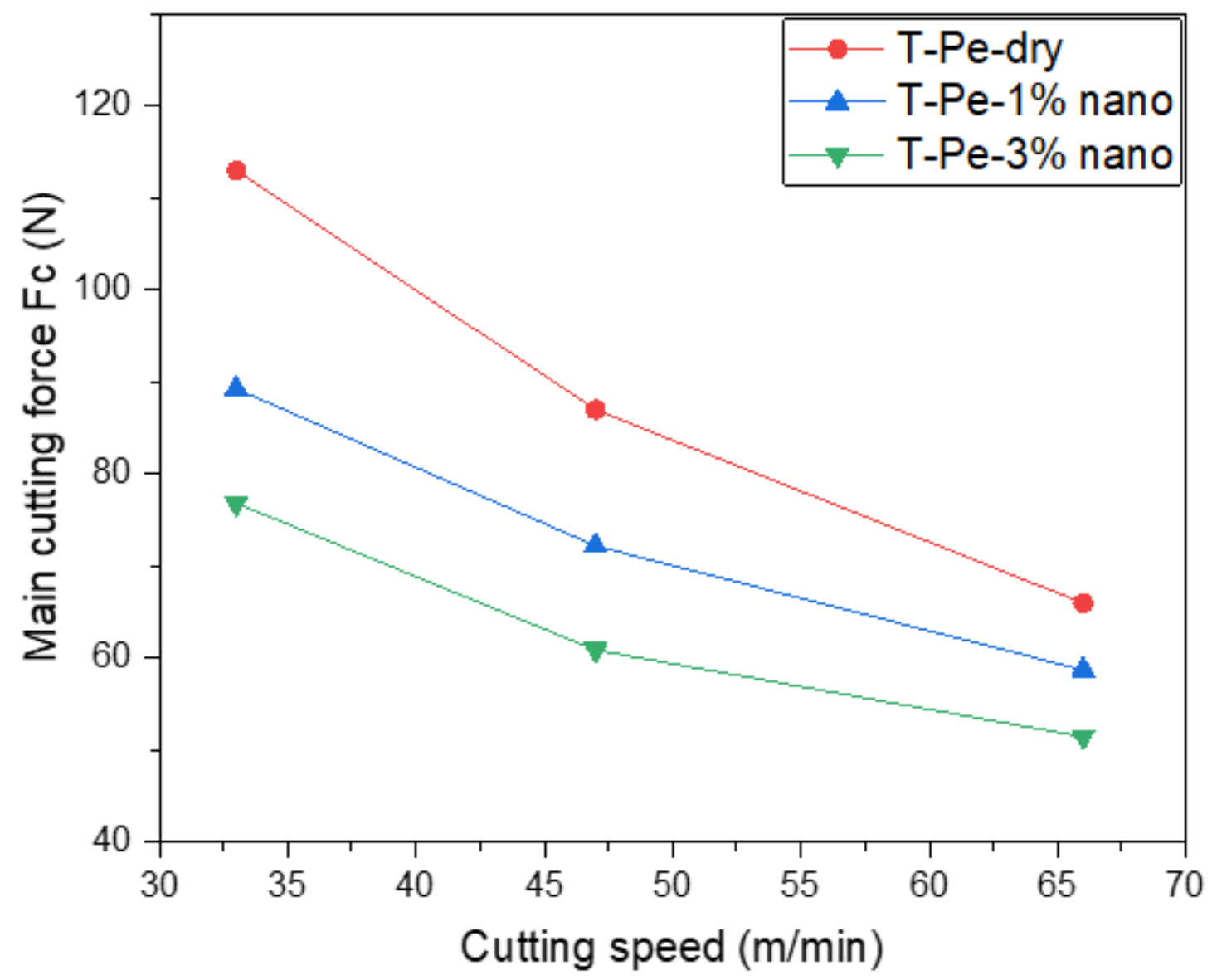

Figure 8

Main cutting force with the cutting speed for different lubrication condition

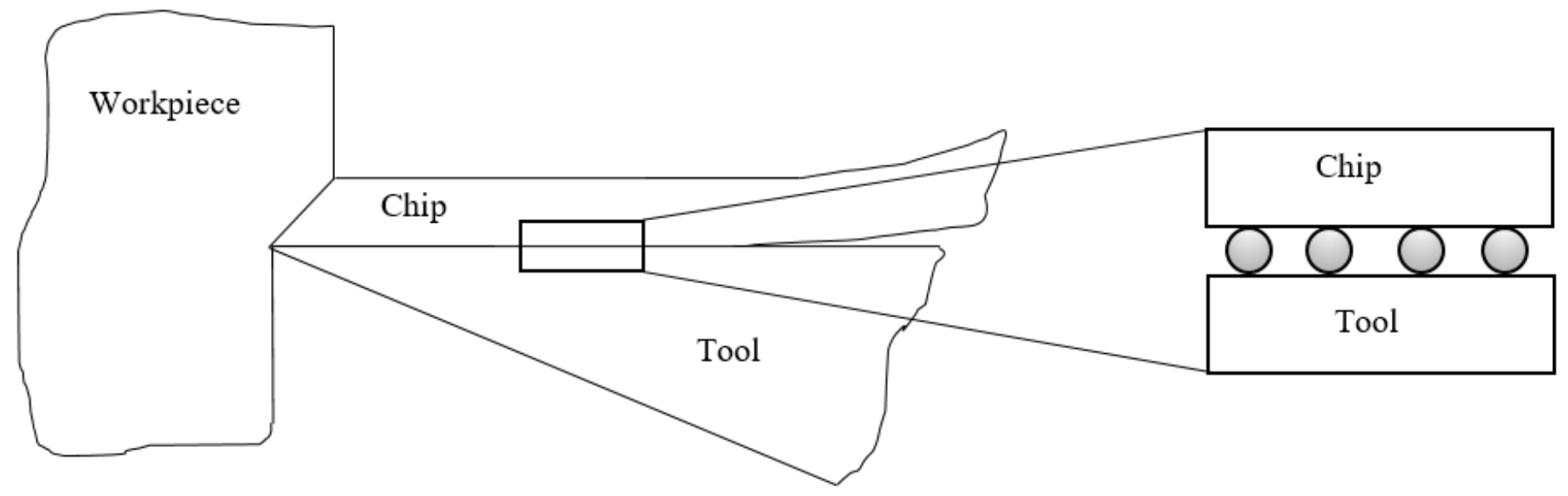

Figure 9 
Nano-bearing effect of carbon nanotubes

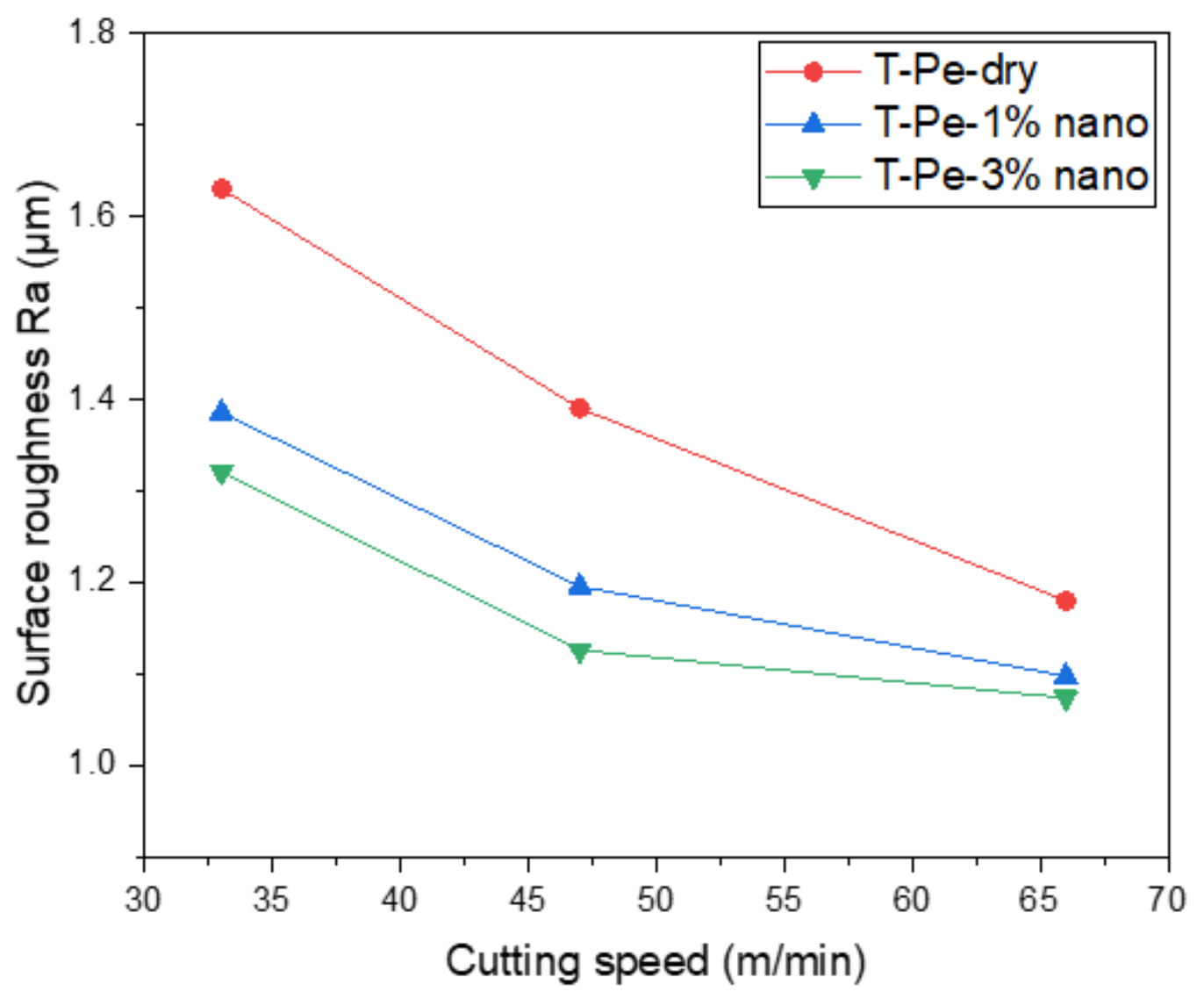

Figure 10

Surface roughness 


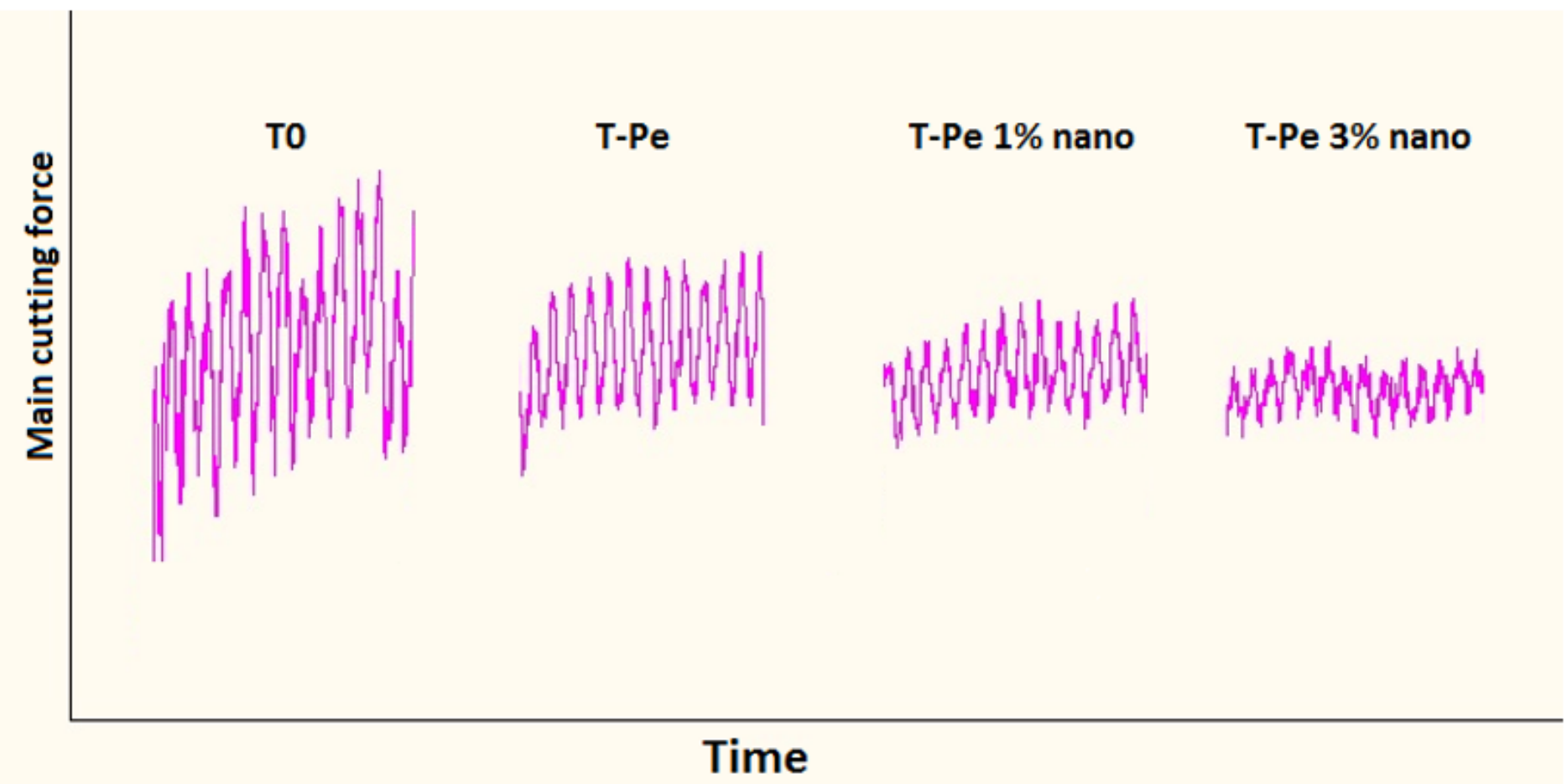

Figure 11

Dynamic main cutting force for different tools at the cutting speed of $66 \mathrm{~m} / \mathrm{min}$

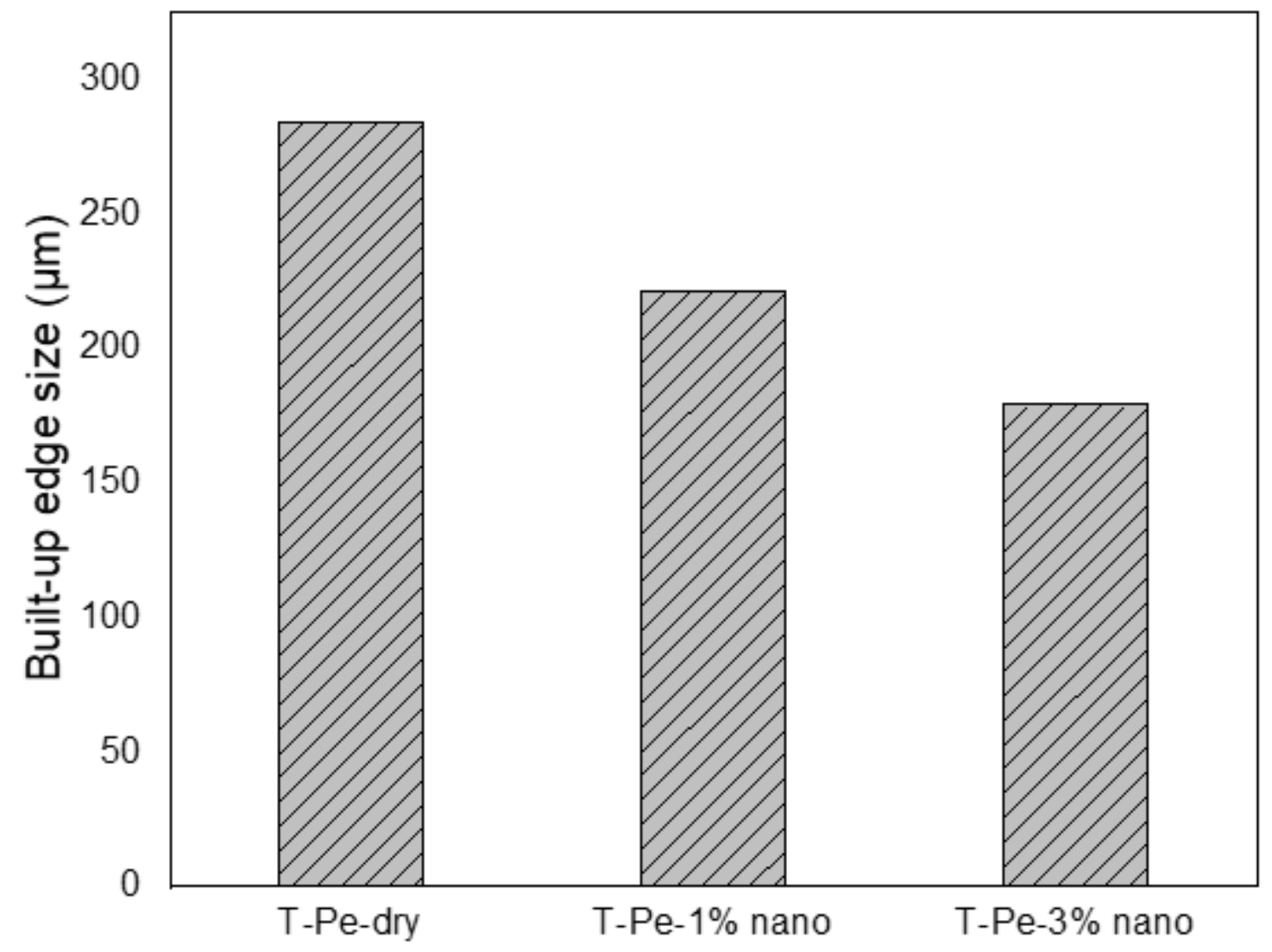


Figure 12

BUE size for different lubrication condition 